\title{
Structuring Pickering Emulsion Interfaces with Bilayered Coacervates of Cellulose Nanofibers and Hectorite Nanoplatelets
}

Yeong Sik Cho ${ }^{\dagger, \|}$, Sung Ho Lee ${ }^{\dagger,+, \|}$, Hye Min Seo ${ }^{\dagger}$, Kyounghee Shin ${ }^{\dagger}$, Min Ho Kang ${ }^{\S, \#, ~ M i n y o u n g ~}$ Lee ${ }^{\S, \#}$, Jungwon Park ${ }^{\S, \#}$, Jin Woong Kim ${ }^{\dagger, *}$

$\dagger$ School of Chemical Engineering, Sungkyunkwan University, Suwon 16419, Republic of Korea

$\$$ Sunjin Beauty Science Co., Ansan 15612, Republic of Korea

$\S$ Center for Nanoparticle Research, Institute for Basic Science (IBS), Seoul 08826, Republic of Korea

\# School of Chemical and Biological Engineering and Institute of Chemical Processes, Seoul National University, Seoul 08826, Republic of Korea

\section{Corresponding Author}

* Prof. Jin Woong Kim, Tel: +82-290-7346, E-mail: jinwoongkim@skku.edu

\section{Theoretical consideration}

The effective density of Pickering emulsion droplets can be calculated using the subsequent approach that platelet particles adsorb on the emulsion surface. The number of particles on the droplet is followed,

$$
N=\frac{4 \pi\left(R^{*}\right)^{2}}{\pi R_{n p}^{2}} \beta=4\left(R^{*} / R_{n p}\right)^{2} \beta
$$

where $\beta$ is the packing fraction of the surface area occupied by the particles. In this emulsion system, the $\beta$ value was determined by 0.83 compared to square packing $(0.785)$ and hexagonal packing $(0.907)$. The mass of platelet particles adsorbed on the single droplet was calculated as

$$
m_{\text {nanoplatelets }}=N \rho_{n p}\left(\frac{4 \pi R_{n p}^{3}}{3}\right)
$$

The mass of the matrix fluid adsorbed on the interfacial membrane layer is obtained by

$$
m_{\text {matrix }- \text { fluid }- \text { immobilized }}=N\left[4 R_{n p}^{2} h-\left(\frac{\pi}{3}\right) h^{2}\left(3 R_{n p}-h\right)\right] \rho_{s}
$$

The effective density of a water droplet of emulsion can be approximated by 


$$
\rho_{d, e f f}=\left(m_{\text {bare }- \text { droplet }}+m_{\text {nanoplatelets }}+m_{\text {matrix }- \text { fluid }- \text { immobilized }}\right) /\left(\frac{4 \pi R_{e f f}^{3}}{3}\right)
$$

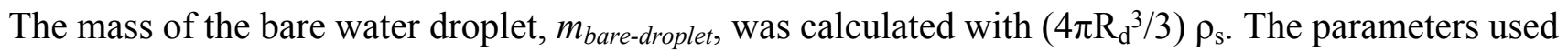
in this emulsion system are $\mathrm{R}_{\mathrm{np}}=10 \mathrm{~nm}, \rho_{\mathrm{np}}=2500 \mathrm{~kg} / \mathrm{m}^{3}, \mathrm{~g}=9.81 \mathrm{~m} / \mathrm{s}^{2}, \rho_{S}=0.96 \mathrm{~kg} / \mathrm{L}$.

\section{Characterizations}

Surface chemistry of AHNPs before and after the modification was analyzed by X-ray diffraction (XRD, D8-advance, Bruker, USA). Thermogravimetric analysis (TGA) was employed to characterize the content of surfactants on AHNPs using an SDT Q600 device (TA Instruments Inc., USA) at a scan rate of $20^{\circ} \mathrm{C} \mathrm{min}^{-1}$. Samples for TEM observation were prepared with $0.001 \mathrm{wt} \%$ of AHNPs in silicone oil. The sample was dropped to deposit on a 300-mesh carbon-coated copper grid (Ted Pella Inc., USA). After complete drying in vacuum at room temperature for overnight, the morphology of AHNPs was observed with a cryo-HAADF-STEM (JEM-2100F, JEOL, Japan) at an accelerating voltage of $120 \mathrm{KV}$. The morphology of BCNFs was observed with an AFM (XE-100, Park system, Korea).

\section{Supplementary data}

Table S1. The type of emulsions determined by conductivity measurements

\begin{tabular}{ccc}
\hline Ratio (water:oil, v/v) & Conductivity $(\mu \mathrm{S} / \mathrm{cm})$ & Type of emulsions \\
\hline $1: 9$ & 0 & $\mathrm{~W} / \mathrm{S}$ \\
$2: 8$ & 0 & $\mathrm{~W} / \mathrm{S}$ \\
$3: 7$ & 0 & $\mathrm{~W} / \mathrm{S}$ \\
$4: 6$ & 0 & $\mathrm{~W} / \mathrm{S}$ \\
$5: 5$ & 326 & Bicontinuous \\
$6: 4$ & 750 & $\mathrm{~S} / \mathrm{W}$ \\
$7: 3$ & 764 & $\mathrm{~S} / \mathrm{W}$ \\
$8: 2$ & 749 & $\mathrm{~S} / \mathrm{W}$ \\
$9: 1$ & 740 & $\mathrm{~S} / \mathrm{W}$ \\
\hline
\end{tabular}

Table S2. Fitting parameter values used of the modified Stokes equation

\begin{tabular}{lllll}
\hline & Avg. R $(\mu \mathrm{m})$ & Avg. $\mu($ Pa.s $)$ & $\mathrm{g}\left(\mathrm{m} / \mathrm{s}^{2}\right)$ & $\rho_{S}(\mathrm{~kg} / \mathrm{L})$ \\
\hline No BCNFs & 19.84 & 380 & 9.81 & 0.96 \\
$0.1 \mathrm{wt} \%$ & 28.22 & 1870 & 9.81 & 0.96 \\
$0.25 \mathrm{wt} \%$ & 37.77 & 3300 & 9.81 & 0.96 \\
$0.5 \mathrm{wt} \%$ & 46.17 & 3800 & 9.81 & 0.96 \\
\hline
\end{tabular}


$\mathrm{R}$ is the radius of emulsion drops, $\mu$ is the viscosity of emulsion systems, $\mathrm{g}$ is the gravitational acceleration, and $\rho_{S}$ is the density of the silicone oil.

(a)

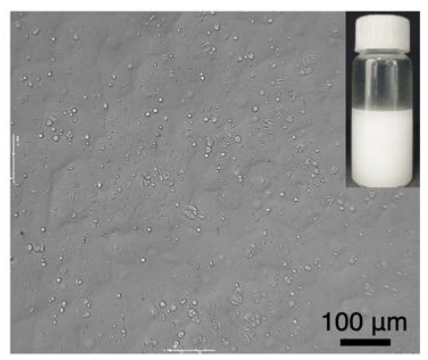

(d)

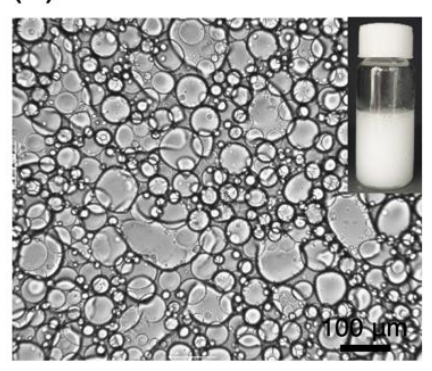

(g)

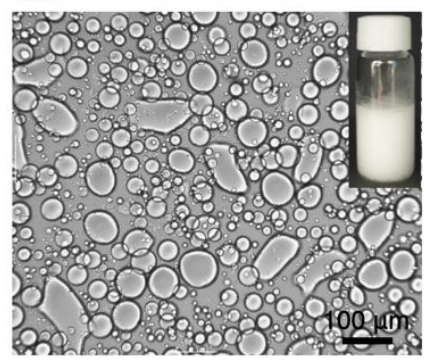

(b)

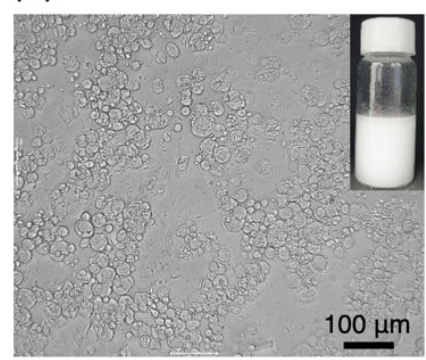

(e)

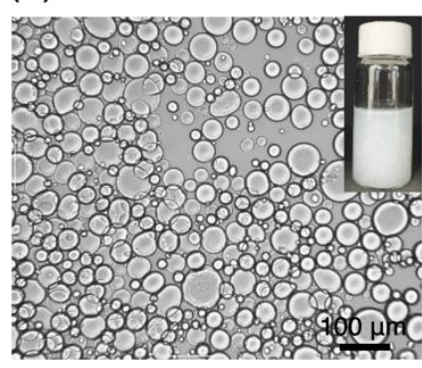

(f)

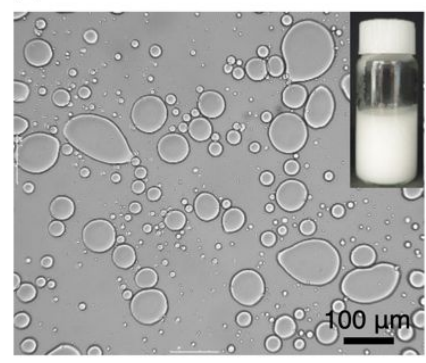

(c)

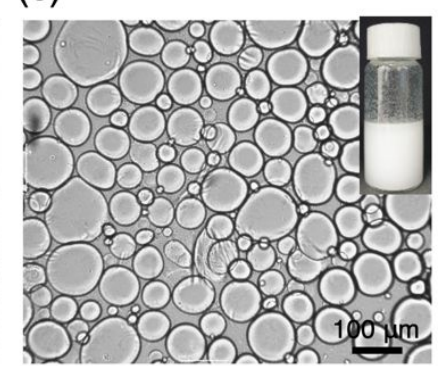

(f)

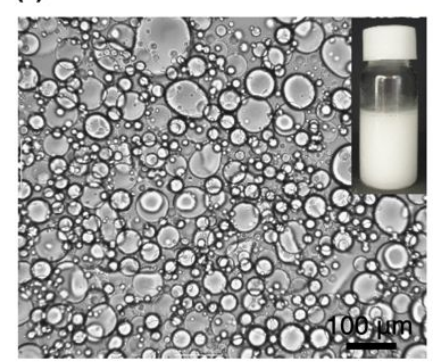

(i)

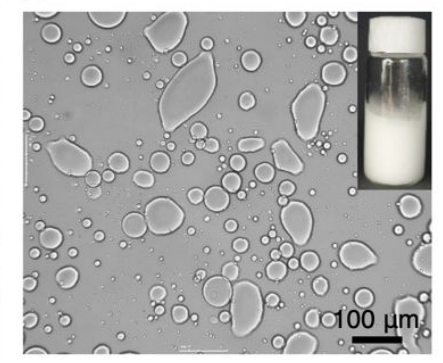

Figure S1. Optical microscope images and actual appearance (inset) of emulsions depending on the ratio of water and silicone oil; (a) 1:9, (b) 2:8, (c) 3:7, (d) 4:6, (e) 5:5, (f) 6:4, (g) 7:3, (h) 8:2, (i) 9:1 $(\mathrm{v} / \mathrm{v})$. The concentration of AHNPs and BCNFs was set to $0.15 \mathrm{wt} \%$ and $0.5 \mathrm{wt} \%$, respectively.

(a)

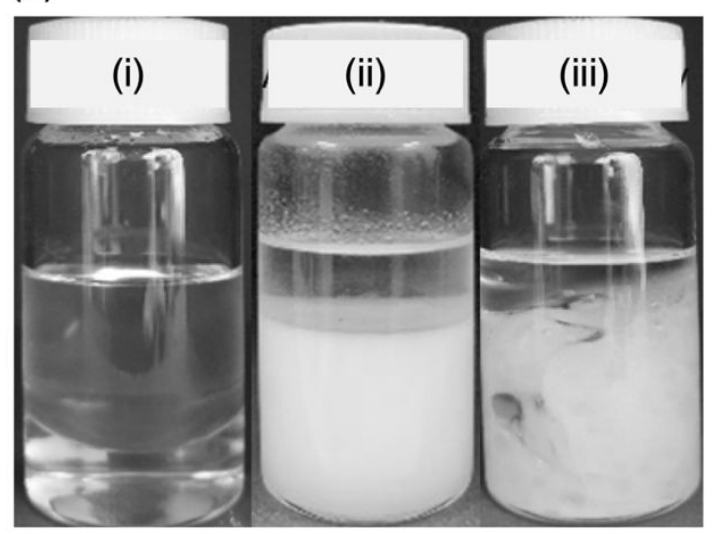

(b)

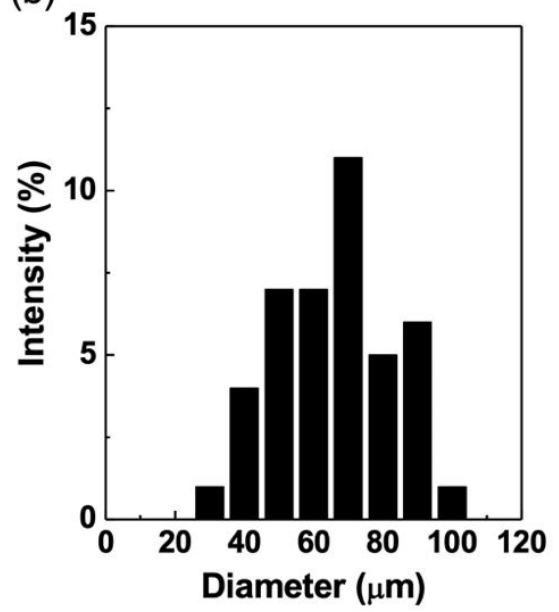

Figure S2. (a) Actual appearance of emulsions with (i) no additive, (ii) AHNPs only, and (iii) BCNFs 
only. (b) Size distribution of Pickering emulsion drops armored with AHNPs and BCNFs. The ratio of water and silicone oil was 3:7 (v/v).

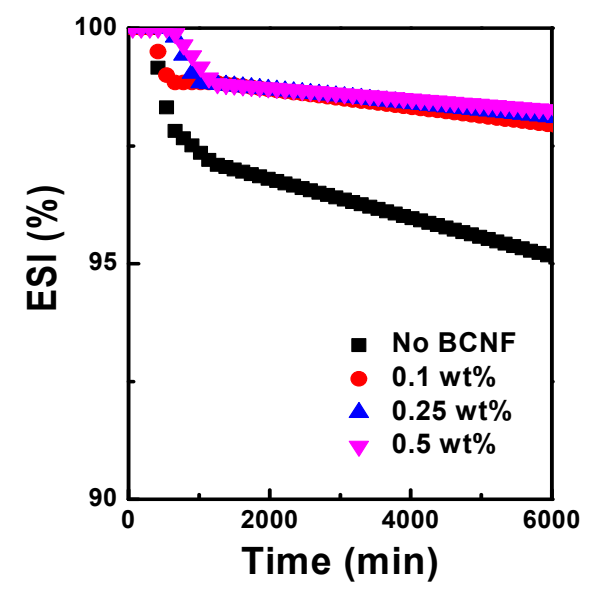

Figure S3. Phase separation kinetics of W/S emulsions prepared with varying BCNF concentration. $[\mathrm{AHNP}]=1 \mathrm{wt} \%$.

(a)

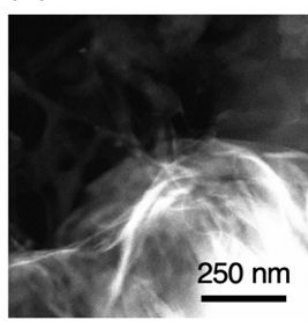

(b)

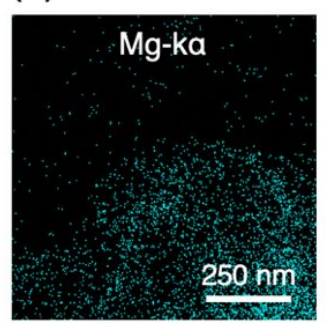

(c)

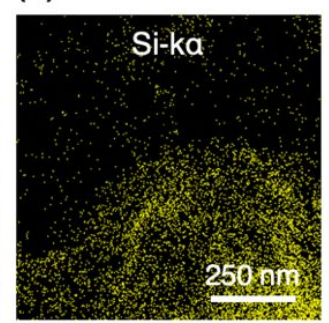

(d)

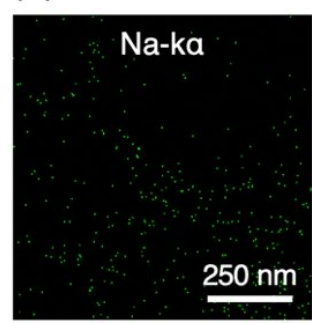

Figure S4. (a) Cryo-HAADF-STEM image of a Pickering emulsion drop. Element mapping of the Pickering emulsion drop by energy-dispersive X-ray spectroscopy: (b) $\mathrm{Mg}$, (c) $\mathrm{Si}$, (d) $\mathrm{Na}$. The Pickering emulsion was prepared with $[\mathrm{AHNP}]=0.15 \mathrm{wt} \%$ and $[\mathrm{BCNF}]=0.5 \mathrm{wt} \%$.

\section{References}

1. Rajinder, P., Modeling of sedimentation and creaming in suspensions and Pickering emulsions. Fluids, 2019, 4(4), 186

2. Laura, Z.; Tobias, B.; Siegel, J. S.; Baldridge K. K.; Ernst, K. H., Pentagonal tiling with buckybowls: pentamethylcorannulene on $\mathrm{Cu}$ (111). Phys. Chem. Chem. Phys. 2012, 14, 13365-13369. 